\title{
A Comparative Study of Poetry Translation in The Story of the Stone From the Perspective of Reception Aesthetics
}

\author{
ZHU Hui-fen \\ Zhejiang Financial College, Hangzhou, China
}

\begin{abstract}
This paper discusses the preservation of the poems' aesthetic effects in translation based on the reception aesthetics theory and the corpus from two English versions of The Story of the Stone. As Chinese traditional poems are part of world cultural treasure, the preservation of aesthetic effects in translation is of great importance in cultural communication. This paper attempts to solve the problem of preserving the aesthetic effects of Chinese poems in translation and keeping the target texts acceptable to the target language readers from the aspects of beauty of musicality, sense and flavor.
\end{abstract}

Keywords: reception aesthetics, poems in The Story of the Stone, aesthetic effects, beauty of musicality, sense and flavor

\section{Introduction}

Translation is not only transference on the language level but also on aesthetic level. With the development of translatology, greater attention has been attached to the aesthetic aspects of translation. Aesthetics is especially important in poetry translation. As the "highest form of literary text" (LIU, 2005, p. 3), poetry is bestowed with the highest degree of musicality, beauty of form and images. These qualities are of great importance to poetry. Without these aesthetic features, a poem cannot be called a poem. As a famous Chinese poet, Ai Qing, puts it "the victory of a poem is not only the victory of its spirit, but also the victory of its aesthetics as well” (GU, 2006, p. 2).

During the process of translating the Chinese poetry, the transference of the aesthetic effects in cultural transmission should be a priority. With a long history, Chinese traditional poems are part of world cultural treasure with rich aesthetic values. Take the poems in the Chinese classic novel, 红楼梦 (The Story of the Stone), for example, they cover a variety of forms of Chinese traditional poems which can be regarded as a typical collection. Contributing to the development of the plots and forming of characters, the poems also feature themselves with their own aesthetic effects in musicality, form and flavor. If properly translated with their aesthetic effects and well received by English readers, these poems can be good examples to demonstrate the special Chinese aesthetic effects in poetry, which will facilitate cross-cultural communication.

However, because of the differences in linguistic codes, people's tastes and values, different languages display their beauty of poems in different ways. As a result, how to maintain the aesthetic effects in poetry translations proves to be a difficulty in translation. According to reception aesthetics theory, reception is defined as "a process creating meaning, which realizes the instructions given in the linguistic appearance of the 
text” (Wessel, 1986, p. 137). Therefore, “emotional activities and aesthetic feeling are of great importance when readers are reading literary works" (ZHENG, 1999, p. 19). In order to achieve the aesthetic effects on readers' end, poetry translation is supposed to provide an aesthetic subject with aesthetic equivalence, enabling the readers to realize the aesthetic value of the text with their own knowledge and experience. In other words, the aesthetic effects of poetry do not simply lie in texts, rather it is realized by the interaction between the target readers and the texts. When a literary work with special aesthetic effects is concerned, it is necessary to study the translation from the aspects of readers' reception.

In order to make a further study of the aesthetic effects in poetry translation, this essay compares some poems selected from Mr. Yang Xianyi’s and Mr. David Hawkes' English versions of The Story of the Stone (红 楼梦) based on the reception aesthetics theory. The comparison is made from the aspects of beauties of musicality, form, sense and poetic flavor. Beauty of verses (musicality) is to be further discussed from the angle of rhyming, rhythm, agreement of sound and sense. A survey has been conducted to provide some useful information about target text readers' different responses to certain aesthetic effects. The native speakers concerned are from different countries, namely Australia, UK, US, Canada, Ireland and New Zealand; they work in different circles such as clerks, teachers or sales managers; and nearly even-numbered male and female interviewees are selected for the survey. To obtain further information about the feedback of the survey, an online interview was also made to find out why they have different responses to different versions.

\section{Beauty of Musicality in Poetry Translation}

Musicality refers to the rhyme, rhythms and alliteration, assonance, etc. (XU, 1992, p. 19). Though the agreement of pronunciation and sense is not often discussed, it is also one factor that contributes to musicality of the verses.

\section{Rhyming}

Rhyme is the sameness of sound between words or syllables, especially the ending of lines of a verse, as in day, away; visit, it; puff, rough. It can be defined as the "nucleus + coda of a syllable, for example, the /ein/ of rain" (Richards \& Schmidt, 2003, p. 459). Rhyming is important in poems. "When we hear one word rhyme with another, we usually experience pleasure in finding harmony between the two. Harmony creates a feeling of completeness, the sense that something has been resolved or finished” (Gill, 1985, p. 50). This is particularly true when we expect a rhyme; our ears wait for the rhyming word, and when it comes, we enjoy the feeling that a meaning, a line, or a stanza has been completed.

Let's look at the following example taken from Chapter One of the novel, a poem by a monk. Though the poem is simple in wording, it reveals the truth of mankind. What impresses readers most is the repeated use of “好 (hao)” and “了 (liao)” in rhyming. For such a long poem, the special effect of the rhyming should be preserved in translation.

[Example 1]

[ST]

好了歌

世人都晓神仙好, 惟有功名忘不了!

古今将相在何方? 荒冢一堆草没了. 


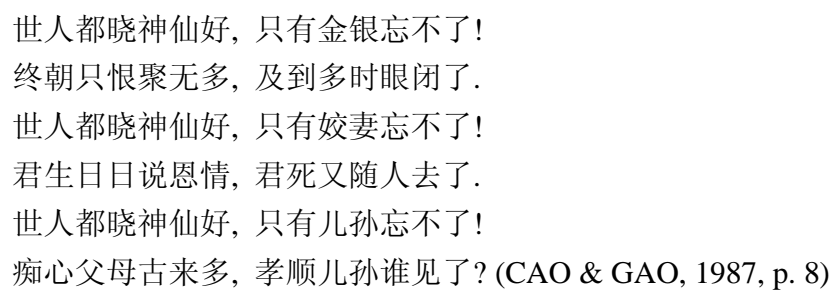

All men long to be immortals

Yet to riches and rank each aspires;

The great ones of old, where are they now?

Their graves are of a mass of briars.

All men long to be immortals.

Yet silver and glove they prize

And grub for money all their lives

Till death seals up their eyes.

All men ling to be immortals

Yet done on the wives they've wed,

Who swear to love their husband evermore

But remarry as soon as he's dead.

All men long to be immortals

Yet with getting sons won't have done.

Although fond parents are legion,

Who ever saw a really filial son?

(YANG \& DAI, 2003, p. 29)

\section{[TT2]}

Men all know that salvation should be won, But with ambition won't have done, have done Where are the famous ones of days gone by? In grassy graves they lie now, every one.

Men all know that salvation should be won, But with their riches won't have done, have done. Each day they grumble they've not made enough. When they've enough, it's goodnight everyone!

Men all know that salvation should be won, But with their loving wives they won't have done. The darlings every day protest their love: But once you're dead, they're off with another one.

Men all know that salvation should be won, But with their children won't have done, have done. Yet thought of parents fond there is no lack, Of grateful children saw I ne'er a one. (Hawkes, Volume 1, 1973, p. 63)

The ST (Source Text) gives us a pleasant feeling of rhyming with the rhyming pattern of AABA with “好 (hao)” and “了 (liao)”. TT2 (target text) also applies a pattern of AABA which is rarely seen in English poetry, while the rhyming pattern of TT1 is not as regular as the ST. The following feet in TT2 gives readers a pleasant feeling:

First stanza: won, done, one;

second stanza: won, done, everyone;

third stanza: won, done, one;

fourth stanza: won, done, one.

Though the TT1 also has the single sound /s/, /n/ and /d/ as the feet, it is relatively less impressive than TT2 in terms of rhyme. The TT2 uses the whole word and syllable as feet. It gives the reader a stronger feeling of completeness.

In the survey, Question One is to test whether the English native speakers prefer rhyming in Yang's version or Hawkes' version. The following statistics suggest that $88.9 \%$ of the readers prefer Hawkes' version (see Table 1). According to one of the interviewees, he likes the rhyming pattern of "won-done-one" very much. The repeated use of the pattern gives readers a pleasant feeling in reading the poem, and the impressive musical effect of the ST is well preserved in TT2 than in TT1. 
Table 1

Statistics of Question 1 in the Survey

\begin{tabular}{|l|l|l|l|l|}
\hline \multicolumn{1}{|c|}{ Statistics } & \multicolumn{2}{c|}{ Numbers } & \multicolumn{2}{c|}{ Percentage } \\
\cline { 4 - 6 } & A & B & A & B \\
\hline $\begin{array}{l}\text { Question 1: Which version do you prefer or give you a } \\
\text { pleasant feeling in terms of rhyming? } \\
\text { A. Yang's version B. Hawkes' version }\end{array}$ & 4 & 32 & $11.1 \%$ & $88.9 \%$ \\
\hline
\end{tabular}

\section{Rhythm}

Rhythm is the pattern produced by emphasis and duration of notes in music or by stressed and unstressed syllables in words. Rhythm can be defined as what "is created by the contracting and relaxing of chest muscles. This causes changes in air pressure” (Richards \& Schmidt, 2003, p. 502). When we are reading a line of poem, we can find that a sequence of stressed and unstressed syllables create regular, or nearly regular, rhythm. For English poems, "regular patterns of stressed and unstressed syllables are called meters" (Gill, 1985, p. 34). For Chinese poems, the rhythms are also influenced by the four tones of the characters in succession, and also the pauses caused by sense groups. For example, the following part of a Chinese poem's rhythm is like this:

$$
\text { 日暮一仓山一远 } 0 \text { 一, / 天寒一白屋一贫 } 0 \text { 一/ }
$$

The rhythms together with the four tones produce a special kind of musicality (GU, 2003, p. 21).

The following poem, by Baoyu, is selected from Chapter Twenty-two. To avoid annoying Daiyu, Baoyu tries to stop Xiangyun who says that one of the actresses looks like Daiyu. This unexpectedly makes both of them angry. Depressed as he is, Baoyu begins to study Zhuangzi's thoughts of Inaction (无为, Wuwei). This verse is written by him when he is studying Zhuangzi's thoughts, the last two lines are written by Daiyu. From his verse, we can feel the love between Baoyu and Daiyu.

[Example 2]

[ST]

参禅偈

你证我证, 心证意证。

是无有证, 斯可云证。

无可云证, 是立足境。

（续）无立足境, 方是干净。(CAO \& GAO, 1987, pp. 159-160)

[TT1]

Should you test me and I test you, Should heart and mind be tested too, Till there remained no more to test, That test would be all of the best. When nothing can be called a test, My feet will find a place to rest. (YANG \& DAI, 2003, p. 607)

[TT2]

I swear, you swear. 


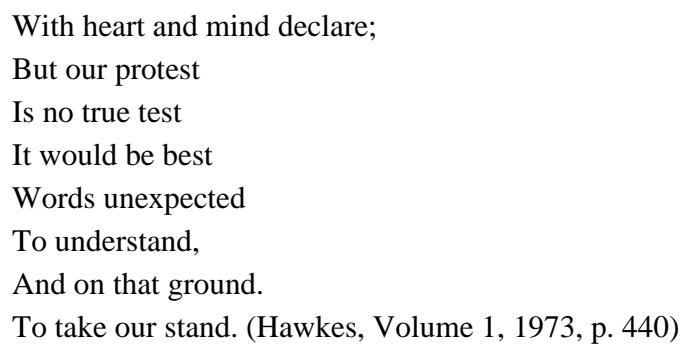

In ST, each line consists of four characters, with the rhythm as follows:

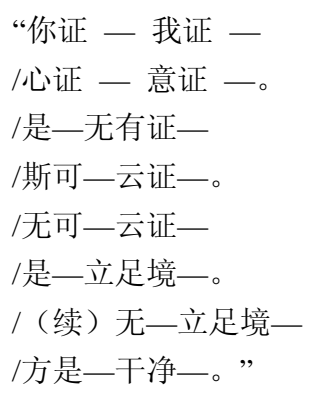

Most pauses in this poem are after two Chinese characters. All of them are ended with Chinese characters with falling tones, such as “证” /zhèng/, “境” /jìng/ and “净” /jìng/. The frequent pauses and short sentences together with the ending characters of falling tones produce a kind of musicality. This kind of rhythm also produces a sense of assertion which expresses Daiyu and Baoyu's deep love to each other. TT1 uses long sentences to translate the poem, and imitates the original shape of the poem. TT2 uses short sentences in translating, and imitates both the shape and the pauses of the original one.

Question Two in the survey attempts to find out which version English native speakers prefer in terms of rhythms. Most of the interviewees prefer Hawkes' version in terms of rhythms (see Table 2). Native speakers tend to enjoy the linguistic beauty of rhythms in longer sentences. It suggests that the rhythms which are preferred by Chinese people in poems are not favored by English native speakers. When translating Chinese poetry into English, we need to take target readers tastes into consideration.

Table 2

Statistics of Question 2 in the Survey

\begin{tabular}{|l|l|l|l|l|}
\hline \multicolumn{1}{|c|}{ Statistics } & \multicolumn{2}{|c|}{ Numbers } & \multicolumn{2}{c|}{ Percentage } \\
\cline { 4 - 6 } & $\mathrm{A}$ & $\mathrm{B}$ & $\mathrm{A}$ & $\mathrm{B}$ \\
\hline $\begin{array}{l}\text { Question2: Which poem do you prefer or give you a } \\
\text { pleasant feeling in terms of rhythms? } \\
\text { A. Yang's version B. Hawkes' version }\end{array}$ & 2 & 34 & $5.6 \%$ & $94.4 \%$ \\
\hline
\end{tabular}

\section{Beauty of Sense in Poetry Translation}

Sense is the meaning of a word, phrase or the way in which a word, sentence, etc. is to be understood. In linguistics, it refers to "the place which a word or phrase (a lexeme) holds in the system of relationships with other words in the vocabulary of a language" (Richards \& Schmidt, 2003, p. 479). By "beauty of sense”, we mainly refer to the beauty of the meaning in poems. 
As a Chinese saying puts it, "Poems express the poets' ideals”. Sense in poems goes beyond the meanings of the words and sentences as separate elements. The most important meaning in a poem is the emotion and the ideal the poet wants to put through.

The following example is a series of poems from the novel The Story of the Stone. These poems are sent by Daiyu to Baoyu to express her sympathy to him. Baoyu was beaten by his father, Jia Zheng, because of his absence from school and his relation with some actresses. Though sympathized by other members of the family, he is not understood by anyone except Daiyu. Deeply moved, Baoyu sends Daiyu several pieces of silk handkerchiefs on which Daiyu writes the following poems. These poems are not only filled with tears and sadness, but with true love.

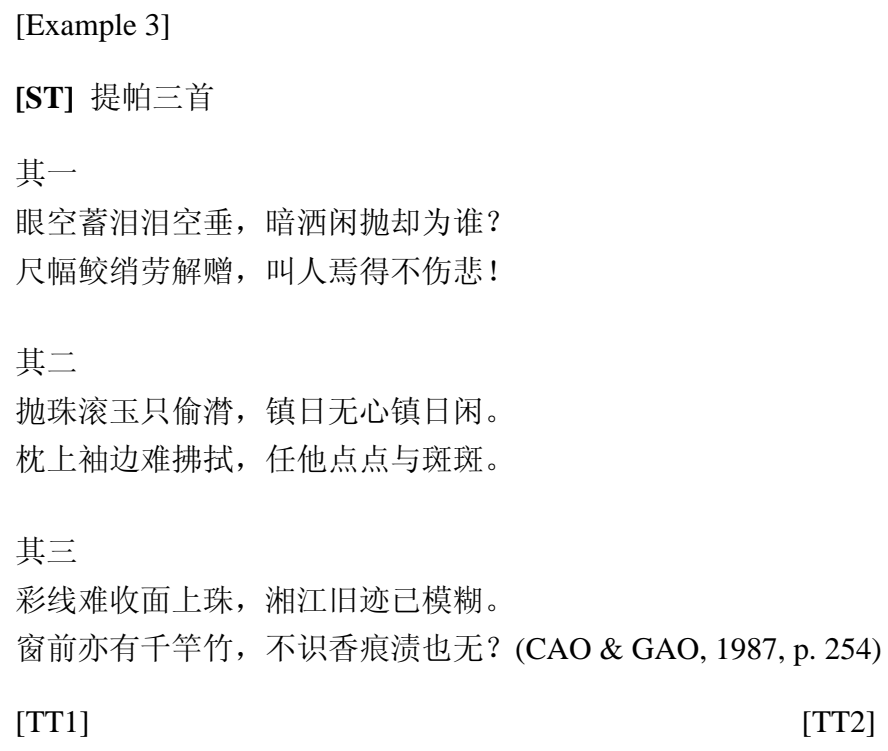

$$
\text { I }
$$

Vain are all these idle tears, Tears shed secretly—-for whom? Your kind gift of a foot of gauze Only deepens my gloom.

\section{II}

By stealth I shed pearly tears, Idle tears the livelong day;

Hard to wipe them from sleeve and pillow, Then suffer the stains to stay.

\section{III}

No silk thread can string these pearls, Dim now the tear-stains of those bygone years; A thousand bamboos grow before my window Is each dappled and stained with tears?! (YANG \& DAI, 2003, p. 947)

\section{I}

Seeing my idle tears, you ask me why These foolish drops fall from my teeming eye: Then know, your gift, being by the merfolk made, In merman's currency must be repaid.

\section{II}

Jewelled drops by day in secret sorrow shed Or, in the night-time, in my wakeful bed, Lest sleeve or pillow they should spot or stain, Shall on these gifts shower down their salty rain.

\section{III}

Yet silk preserves but ill the Naiad's tear: Each salty trace of them fast disappears. Only the speckled bamboo stems that grow Outside the window still her tear-marks show. (Hawkes, Volume 2, 1973, p. 168)

In the survey, Question Three and Question Four are about the above series of poems. Question Three is to find out which version the readers prefer; Question four is about readers' responses to the emotion expressed in 
the translated poems. The following table shows that $94.4 \%$ of the interviewees prefer Hawkes' version and they think his version expresses the love between Daiyu and Baoyu better. To meet target readers' taste, Hawkes' version used personal pronouns more, such as my, you, and your, to express the feelings more directly. What's more, the image of Xiang River which is about a Chinese traditional folk lore about the tear-stained bamboo is transferred to the household Western the image of Naiad. This probably makes the target readers like Hawkes' version more.

Table 3

Statistics of Question 3 and Question 4 in the Survey

\begin{tabular}{|l|l|l|l|l|}
\hline \multirow{2}{*}{ Questions } & \multicolumn{2}{c|}{ Nutatistics } & \multicolumn{3}{c|}{ Percentage } \\
\cline { 4 - 6 } & A & B & A & B \\
\hline $\begin{array}{l}\text { Question3: This is a poem about love, which one do you prefer? } \\
\text { A. Yang's version B. Hawkes' version }\end{array}$ & 2 & 34 & $5.6 \%$ & $94.4 \%$ \\
\hline $\begin{array}{l}\text { Question4:Which poem do you think express the love best? } \\
\text { A. Yang's version B. Hawkes' version }\end{array}$ & 8 & 28 & $22.2 \%$ & $77.8 \%$ \\
\hline
\end{tabular}

Another aesthetic feature of Chinese poems is the indirect discourse pattern or ways of expressing. The ways of the expressing are different in eastern and western cultures. It is believed that the oriental discourse pattern is inductive while the English discourse pattern is deductive (R. Scollon \& S. W. Scollon, 2000, p. 229). It can be illustrated as follows (see Figure 1). As for the ways of expression, Chinese classic poems tend to express the feeling in an indirect way while English poems are usually straightforward in the way of expression.

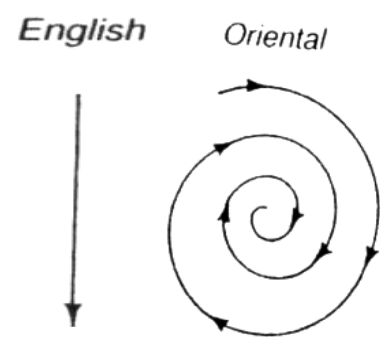

Figure 1. Comparison of English discourse pattern and Oriental discourse pattern.

The indirect expression is also a demonstration of the beauty of Chinese traditional poems. Example 4 is a poem from Chapter Twenty-eight. Baoyu makes this poem in a party with some friends. The ST poem expresses how much a wife misses her husband. In the ST, not a single word or sentence directly expresses the love of a wife to her husband. But from the frequent repetition of the Chinese character “不” (not, pinyin: bu), we can deduce that she is deeply nostalgic. The endless tears, sleepless night, and everything has betrayed the wife's longing for her beloved husband.

[Example 4]

\section{[ST]}

滴不尽相思血泪抛红豆,
开不完春柳春花满画楼;
睡不稳纱窗风雨黄昏后,
忘不了新愁与旧愁;
咽不下玉粒金莼噎满喉,
照不见菱花镜里形容瘦。 


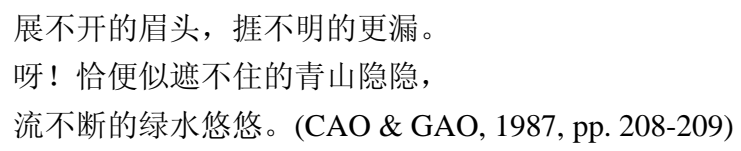

For such a beautiful, but indirect poem, if translated in an indirect discourse pattern, the target readers might not understand the strong love in it. However, if translated in direct discourse pattern, the poem will be too passionate to be appreciated as Chinese traditional poem. Moreover, the direct discourse pattern might ruin the beauty in Chinese traditional poems and be improper for the overall background of the novel. Yang and Hawkes have provided us with two versions in indirect discourse pattern. This has preserved the beauty of indirectness in Chinese poems. However, since the poem is translated in an indirect way, translators need to provide readers' schemata with "gaps" which urge readers to fill in and make the plots or pictures in the poem as a whole. Only in this way can readers play an active role in reading to make the bits into a complete story or picture in order to realize the aesthetic actualization. Both TT1 and TT2 translated the poem in an indirect way. The following table shows the direct and indirect words or phrases used to express the wife's feeling.

Table 4

Comparison of Yang's and Hawkes' Direct and Indirect Ways of Expression (Example 4)

\begin{tabular}{|c|c|c|}
\hline & Direct & Indirect \\
\hline Yang's version & $\begin{array}{l}\text { longing; sorrow } \\
\text { ( } 2 \text { words in total) }\end{array}$ & $\begin{array}{l}\text { endless tears; sleepless at night; cannot forget: choking; wan } \\
\text { reflection; frown, long night } \\
\text { ( } 6 \text { words or expressions in total) }\end{array}$ \\
\hline Hawkes' version & $\begin{array}{l}\text { desolation; blue; } \\
\text { ( } 2 \text { words in total) }\end{array}$ & $\begin{array}{l}\text { weeping tears; love-beans; awake in the dark; choked with tears; can't } \\
\text { swallow food and drink; thin; pale; } \\
\text { ( } 6 \text { words or expressions in total) }\end{array}$ \\
\hline
\end{tabular}


As is shown in the above table, both TT1 and TT2 are comparatively indirect in their expression. The number of words or phrases that directly states the wife's feeling is much less than that of indirect ones in both versions. All the indirect elements contribute to the central image of a sorrowful wife missing her husband from morning till night. In TT1, though the key word "longing" is used, readers might not be sure why the woman is sorrowful and what she is longing for in this poem. Though indirect, TT2 is easy to be understood by target readers. The use of element “ love-beans” (红豆), though indirect, associate readers directly with a love story. Hawkes successfully uses this indirect element to efficiently enact readers’ schema of love stories and connect the other bits in this poem as a whole.

The following statistics (see Table 5) is about native speakers' responses to the two different versions of the above poem. In Question Five, most of the interviewees think that Hawkes' version is indirect in the way of expression. Hawkes' indirect way of translation has provided a good example for maintaining the indirect beauty in Chinese poems and making readers understand the poem. As for the Question Six, it shows that 66.7\% of the native speakers prefer Yang's version. Probably, native speakers tend to find it much easier to understand Chinese culture, such as the indirect way of expression, with the development of effective culture exchanges.

In Question Seven, we supposed that most of the TT readers could not understand Yang's version in the following, so we designed this question in the survey. Readers were supposed to be confused about this sentence, "rice like jade and wine like gold”, because of culture difference.

\section{[ST]：咽不下玉粒金莼噎满喉}

A. Hawkes' version: Still can't swallow food and drink, 'cos I'm choked with tears.

B. Yang's version: Choking on rice like jade and wine like gold

However, statistics shows that $66.7 \%$ the native speakers like Yang's version better. From the statistics, native speakers understand jade-like rice (玉粒) and gold-like wine (金莼) in Yang's version with the wide-spreading of Chinese restaurants around the world. What's more, they might find the colors beautiful with mysterious feeling.

Table 5

Statistics of Question Five, Question Six and Question Seven in the Survey

\begin{tabular}{|l|l|l|l|l|}
\hline \multirow{2}{*}{ Questions } & \multicolumn{2}{|c|}{ Statistics } & \multicolumn{2}{|c|}{ Percentage } \\
\cline { 3 - 6 } & A & B & A & B \\
\hline $\begin{array}{l}\text { Question 5: Version A is ( ) in the way of expression. } \\
\text { A: indirect B: direct }\end{array}$ & 32 & 4 & $88.9 \%$ & $11.1 \%$ \\
\hline $\begin{array}{l}\text { Question 6: Which version gives you a pleasant feeling in terms of expression? ( ) } \\
\text { A. Hawkes' version B. Yang's version }\end{array}$ & 12 & 24 & $33.3 \%$ & $66.7 \%$ \\
\hline $\begin{array}{l}\text { Question 7: Which sentence do you prefer? ( ) } \\
\text { ST: 咽不下噎满喉 }\end{array}$ & 12 & 24 & $33.3 \%$ & $66.7 \%$ \\
$\begin{array}{l}\text { A. Hawkes' version: Still can't swallow food and drink, 'cos I'm choked with tears. } \\
\text { B. Yang's version: Choking on rice like jade and wine like gold }\end{array}$ & & & & \\
\hline
\end{tabular}

As what is mentioned in reception aesthetics theory, readers' reception is dynamic. When we need to translate something culture-loaded, such as the indirect way of expression and the culture-specific items, native speakers' reception need to be taken into consideration in a dynamic way. If the readers' understanding of the ST culture has developed, we need not always apply the technique of domestification, such as deletion and abstraction. With proper foreignization, the beauty of the ST can be preserved and some culture-loaded ideas can be transferred effectively to another culture. 


\section{Beauty of Poetic Flavor in Poetry Translation}

Flavor usually refers to the taste or smell of food, while the poetic flavor, as one of the poetry aesthetic effects, "is a kind of non-material intent of poetic mind, which lies in the poetic work itself. It is the essence of poetry, and the retention of the poetic translation is the highest ideal for all literary translations" (ZHANG, 2004, p. 45). Gu Zhengkun defines it as "the comprehensive aesthetic feeling of the reader towards the poems' sound, vision, sense, etc.” (GU, 2003, p. 36). There're some overlaps among the beauty of verses, form and beauty of sense, which are mainly about the external features of the poems. In this part, we will only discuss the poetic flavor which is the internal feature of poems. Sometimes, what a poem is about is as beautiful as a picture, or as pleasant to listen to as a song, or as vague as a riddle.

Sometimes, what is described in a poem is as beautiful as a picture. Here is another example from Chapter Eighteen, which is about the beautiful scenery in Prospect Garden.

[Example 5]

[ST] 有风来仪

秀玉初成实, 堪宜待风凰。

竿竿青欲滴, 个个绿生凉。

迸砌妨阶水, 穿帘碍鼎香。

莫摇清碎影, 好梦昼初长。(CAO \& GAO, 1987, p. 129)

[TT1]

\section{Where the Phoenix Alights}

The fruit fresh formed on jade stalks rare

Makes for the phoenix fitting fare;

So green each stem they seem to drip

With coolness seeping from each verdant dip.

Bursting through stones, they change the water's track;

Piercing through stones, they change the water's track;

Let none disturb these chequered shades.

That sweetly she may dream till daylight fades. (YANG \& DAI, 2003, p. 495)

[TT2]

\section{The Phoenix Dance}

Perfected now at last, this place is fit

For bird of Paradise to enter it.

Each graceful wand lets fall a dewy tear;

Each glossy leaf breathes coolness on the air.

Through narrow-parted blocks the pent stream leaps;

Through chinks of blind the incense thinly seeps.

Let none the checkered shade with violence rude

Disrupting, on the slumberer's dreams intrude! (Hawkes, Volume I, 1973, p. 369)

As is shown in the following table, 66.7\% of the interviewees prefer Yang's version in terms of color. When asked why, one of them gives the words "jade" and "drip”. From the native speakers' responses, we know that Yang's version has preserved the beauty of color better. The poem in ST depicts the picture of the 
jade-like bamboo. The color of the bamboo is so fresh that the juice of it is likely to drip, so nice that it makes people feel cool in summer. In TT1, the words "jade", "drip" and "coolness" describe the kind of green color in ST; but in TT2, the color of the bamboo is not mentioned directly with only "dewy tear" and "coolness" giving some hints about the color. From the aspect of color, TT1 is better than TT2.

Table 6

Statistics of Question Eight in the Survey

\begin{tabular}{|l|l|l|l|l|}
\hline \multirow{2}{*}{ Questions } & \multicolumn{2}{|c|}{ Numbers } & \multicolumn{2}{c|}{ Percentage } \\
\cline { 3 - 5 } & A & B & A & B \\
\hline $\begin{array}{l}\text { Question8: Both the poems are about the green bamboo, which one } \\
\text { do you prefer in terms of color?( ) } \\
\text { A. Hawkes' version B. Yang's version }\end{array}$ & & 24 & $33.3 \%$ & $66.7 \%$ \\
\hline
\end{tabular}

\section{Conclusion}

This paper discusses the preservation of the poetry's aesthetic effects in translation. As far as the beauty of sound is concerned, we need to maintain the rhyme, rhythm. As for the sense and flavor, the basic aesthetic features of Chinese poems should also be maintained, like the indirect discourse pattern. TT readers' reception should be taken into consideration in translation. From a diachronic view, readers' reception is dynamic, which changes with time and the development of cultural exchanges. From a synchronic angle, factors like TT readers' values, customs and education backgrounds should also be considered. It can be concluded that a better understanding of TT reader' reception is conducive to the effective transmission of Chinese traditional poetry to the TT readers.

\section{References}

CAO, X. Q., \& GAO, E. (1987). The story of the stone. Changsha: Yuelu Press.

Gill, R. (1985). Mastering English literature. London: Macmillan Education Ltd.

GU, Z. K. (2003). China and West: Comparative poetics and translatology. Beijing: Tsinghua University Press.

Hawkes, D. (1973). The story of the stone. London: Penguin Group.

LIU, H. W. (2005). Readers' aesthetic construction in C/E translation of Chinese poems. Shanghai: Shanghai Translation Publishing House.

Richards, J. C., \& Schmidt, R. (2003). Language teaching \& applied linguistics. Beijing: Foreign Language Teaching and Research Press.

Scollon, R., \& Scollon, S. W. (2000). Intercultural communication: A discourse approach. Beijing: Foreign Language Teaching and Research Press.

Wessel, F. (1986). Theories of literature in the twentieth century: Structuralism, Marxism, aesthetics of reception, semiotics. England: C. Hurst \& Co. (Publishers) Ltd.

XU, X. C. (1992). On Chinese verse in English rhyme: From the book of poetry to the romance of the Western Bower. Beijing: Beijing University Press.

YANG, X. Y., \& DAI, N. D. (2003). A dream of red mansions. Beijing: Foreign Languages Press.

ZHANG, B. H. (2004). The translation of poetic flavor in Chinese poetry. Xi'an: Foreign Language Education.

ZHENG, D. H. (1999). On priority of aesthetic effects in literary translation. Beijing: Chinese Translators Journal. 